\title{
Condylomata of the uterine cervix and koilocytosis of cervical intraepithelial neoplasia
}

\author{
SILVANA PILOTTI,* FRANCO RILKE, * GIUSEPPE DE PALO, $\dagger$ \\ GABRIELLA DELLA TORRE, $\ddagger$ LOREDANA ALASIO*
}

\begin{abstract}
From the *Division of Anatomical Pathology and Cytology, $\dagger$ Division of Clinical Oncology A, and $\ddagger$ Division of Experimental Oncology A, Istituto Nazionale per lo Studio e la Cura dei Tumori, Via Venezian 1, 20133 Milan, Italy
\end{abstract}

SUMMARY In 202 women with koilocytotic atypia in cervical smears, 136 had predominantly smalet condylomata of the uterine cervix, and 66 had cervical intraepithelial neoplasia (CIN) of varying degree either with koilocytosis of the neoplasia or associated with condylomata. Koilocytosis correlated well with the histological diagnosis of condylomata, but occasionally it obscured the cytological evidence of CIN. Human papilloma virus particles were found in the cells of condylo $\bar{z}$ mata in 10 cases and in those of CIN II with koilocytosis in two cases of 21 examined ultrastruc turally. There was evidence that the condyloma of the uterine cervix is a well-defined morphologicato entity and also that cytopathic changes similar to those seen in condylomata are present in some cases of CIN.

Condylomata acuminata are papillomatous lesions that arise mainly in the genital and anal regions of both sexes. The lesion is caused by a DNA tumour virus, the human papilloma virus (HPV), which forms the group of the papovaviruses with the polyoma viruses and the simian virus 40 . The virus detected in condylomata acuminata ${ }^{12}$ has been defined as HPV 6 in a recent classification ${ }^{3}$ and differs biochemically 4 and immunologically ${ }^{5}$ from that of the common wart. Studies on viral oncogenesis have shown that a wart has a unicellular origin, whereas condyloma acuminatum has a multicellular one. ${ }^{6}$ The multicellular derivation stresses the importance of environmental factors in the formative process of condyloma acuminatum, which is considered a transmittable venereal disease ${ }^{78}$ with a high incidence in populations who show sexual promiscuity. ${ }^{9}$ Condylomata acuminata occasionally undergo malignant transformation. ${ }^{10}$

In the uterine cervix condylomata acuminata are rare whereas less papillomatous and even flat lesions are more common. The latter have been considered possible early precursors of the exophytic lesions. ${ }^{11}$ Their unsuspected frequency in asymptomatic women has been particularly stressed. ${ }^{12}$ The cytological appearances in smears of early and florid condylomatous proliferations are similar. One of their most striking features is the cytoplasmic

Accepted for publication 17 December 1980 clearing with nuclear atypia (koilocytotic atypia $\left.{ }^{13}\right)$ which is now known to be a viral cytopathic effecto Ultrastructural investigations have shown the presence of papilloma virus particles in flat cervicatif condylomata, ${ }^{14}$ noncondylomatous warty lesions, ${ }^{15-17}$ koilocytotic cells, ${ }^{18}$ and exfoliate koilocytotic and dyskeratotic cells of flat condylo? mata of the uterine cervix. ${ }^{19}$ The similarity of condylomatous lesions to mild and moderate dysplasia of the uterine cervix and their possible association in some patients have been recogo nised. ${ }^{1120-22}$ However, the problem of the possible significance of these viral lesions in the genesis of cervical carcinoma is still unsolved.

On the premise that koilocytotic cytopathis effects can be seen histologically not only in condy? lomata but also in some cases of cervical intra今 epithelial neoplasias (CIN), ${ }^{23}{ }^{24}$ our study evaluates by histology and, in part, by electron microscopy the reliability of the cytological finding of koilocytoties atypia in both benign and CIN-derived cells is cervical smears and evaluates the possible signiffe cance of the association of condylomata and CIN and of the condyloma-like features occasionally displayed by CIN.

\section{Material and methods}

We examined 202 women aged between 17 and $6 \overline{2}$ years (mean 32.5 years, median 32 ) whose cervical 
vaginal, endocervical smears (CVE) taken at the outpatient clinic of this institution contained koilocytotic cells or cells deriving from CIN with koilocytotic changes or both and whose biopsy material taken from the uterine cervix showed condylomata or CIN with koilocytosis, or both. Only four patients were postmenopausal. All patients underwent colposcopic examination and had directed biopsy specimens taken from their cervix within a month of the cytological diagnosis. Fifty-five patients with condylomata only had at least one repeat smear six months after biopsy.

The smears were stained with Papanicolaou's method. The biopsy material for light microscopy was fixed in Bouin's fluid, embedded in paraffin, and the $5 \mu \mathrm{m}$-thick sections were stained with haematoxylin-eosin and PAS-haematoxylin with and without diastase pretreatment. The search for viral particles by electron microscopy was made in one vaginal and 21 cervical biopsy specimens. Of the former and of 15 cervical specimens, one-half were processed for electron microscopy. They were fixed for 2 hours at $4^{\circ} \mathrm{C}$ in $0.1 \mathrm{M}$ phosphate-buffered $2.5 \%$ glutaraldehyde and after fragmentation, postfixed for 2 hours at $4^{\circ} \mathrm{C}$ in $0 \cdot 1 \mathrm{M}$ Millonig buffer containing $1 \% \mathrm{OsO}_{4}$, dehydrated through graded alcohols, and embedded in Epon. Suitable samples were selected under the light microscope from $1 \mu \mathrm{m}$-thick sections stained with $1 \%$ methylene blue and $1 \%$ azure II. The tissue areas of interest selected on histological sections were removed from paraffin blocks of the remaining six cervical specimens, deparaffinised in xylene, and processed for electron microscopy after aldehyde fixation. Ultrathin sections of all biopsy specimens were collected on 150 mesh naked grids, double stained with uranyl acetate and lead citrate, and then examined with a Philips EM 300 electron microscope at $60 \mathrm{kV}$. Colposcopic examination was performed with a Zeiss colposcope before and after treatment with acetic acid and Lugol's solution.

In one case concomitant vulvar and in another vaginal condylomata acuminata were present, and biopsy specimens were taken. We examined the male partners of two patients at the same time and found penile condylomata acuminata which were biopsied.

\section{Results}

\section{HISTOLOGY}

In $136^{*}$ cases $(67 \cdot 3 \%)$, biopsy material taken from the uterine cervix showed the presence of condylomata (group 1); in $39(19.3 \%)$ there were condy-

* In one case with cervical condyloma a nonadjacent invasive squamous cell carcinoma (stage IB) was found. lomata and adjacent CIN (group 2), and in 27 cases $(13.4 \%)$ CIN with koilocytosis of varying degree in the absence of condylomata was found (group 3). Mean and median ages of the first group were respectively 32.2 and 31 years; mean and median ages of the second and third groups combined were respectively 33.7 and 32 years. The vast majority of the condylomata were small and flat or only moderately papillomatous. Fully developed condylomata acuminata were seen in only six cases. Occasionally, there was an association of the various types.

\section{Group 1}

In 104 out of the $136(76.5 \%)$ cases with cervical condylomata, the histological picture was characterised by a honeycomb pattern of the epithelium with few cells in the superficial and intermediate layers. Cell size had increased, and a clear perinuclear halo not containing glycogen was present. The basal layer was well preserved. The nuclei of the cells with the halo were often eccentric and some of them were hypochromatic showing a "dusty" appearance while others were hyperchromatic and pyknotic. The nuclei were occasionally multiple. The mitotic index was low and no abnormal mitotic figures were found. The degree of acanthosis and hyperkeratosis of the epithelium and the amount of small cell infiltration of the underlying stroma were variable but usually mild to moderate. This appearance is defined as condyloma type 1 (Fig. 1a).

In the other 32 cases $(23.5 \%)$ the changes were more severe. The majority of the cells had a very large cytoplasm, which was almost completely replaced by the koilocytic halo. The honeycomb pattern covered the whole thickness of the epithelium, with disorder of the stratification. The nuclei were hyperchromatic and often bizarre; multinucleation was common, as was karyorrhexis. In the intermediate layer there was occasional single cell keratinisation. Within the epithelium inflammatory cells were present. The mitotic index was also low in this lesion, and no abnormal mitotic figures were found. The more severe lesion described is defined as condyloma type 2 (Fig. 2a). An attempt to differentiate type 2 condylomata from CIN I or mild dysplasia with koilocytosis was unsuccessful.

\section{Group 2}

In $39(19.3 \%)$ cases, single or multiple condylomata type 1 and 2 as described above were found adjacent to foci of CIN. In addition, a variable number of cells of the neoplastic lesions showed koilocytosis (Figs 3a and b). CIN II was associated with condyloma type 1 in 12 cases and with condyloma type 2 in six cases, and CIN III, respectively, in 15 and six cases. 


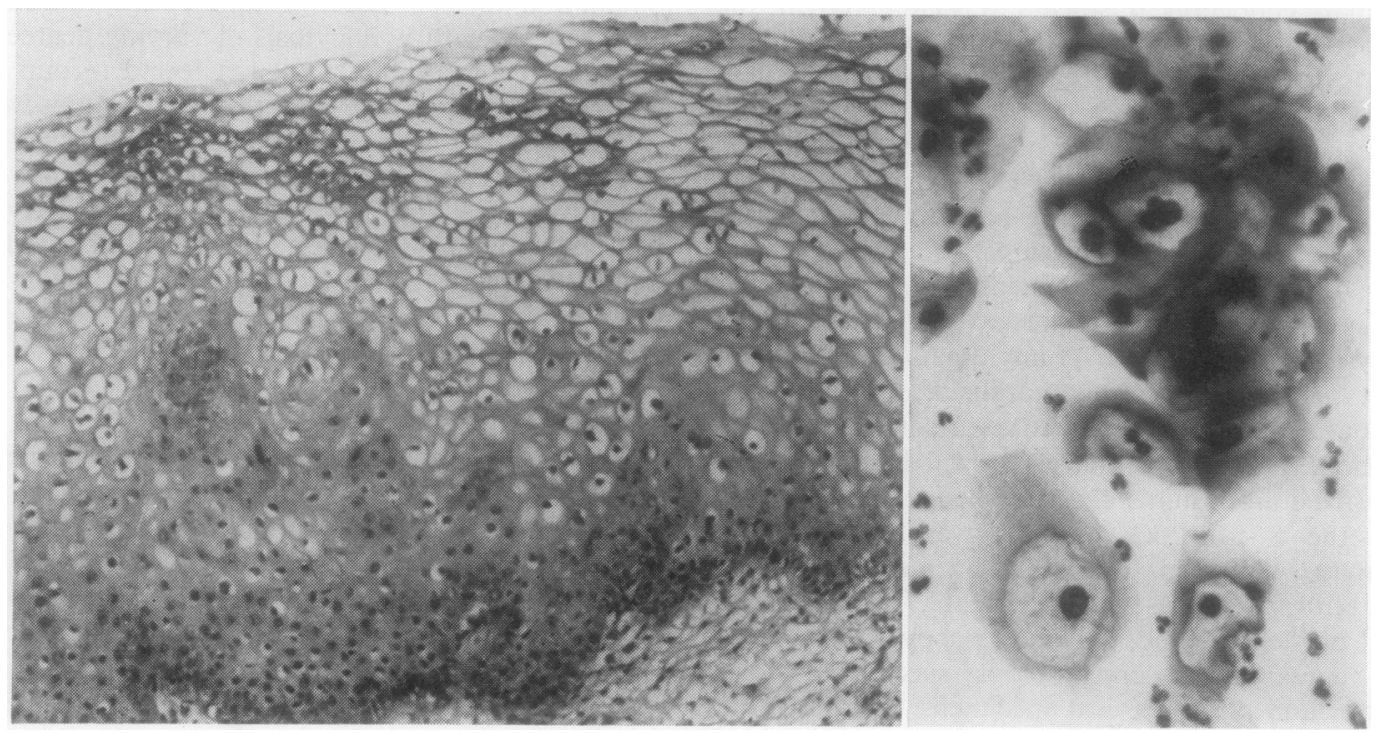

1a

$1 \mathrm{~b}$

Fig. 1a Flat condyloma of the uterine cervix type 1. Haematoxylin and eosin $\times 100$

Fig. 1b Cytology of flat condyloma type 1. Papanicolaou $\times 400$

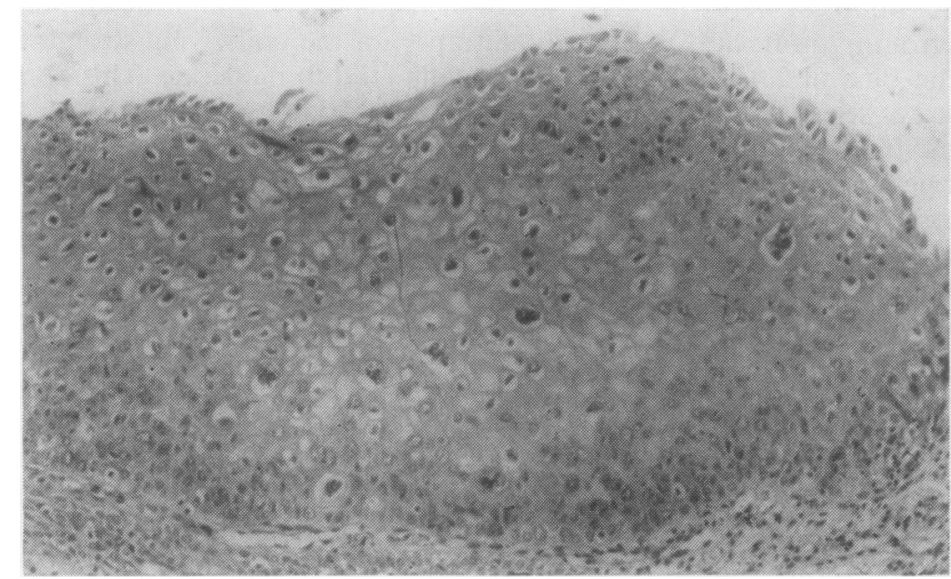

Fig. 2a Flat condyloma of the uterine cervix type 2. Haematoxylin and eosin $\times 100$

Fig. 2b The cytology of flat condyloma type 2. Papanicolaou $\times 250$

\section{Group 3}

Of the 27 cases $(13.4 \%)$ with CIN with koilocytosis and no condyloma, 12 were rated as CIN II (Fig. 4a) and 15 as CIN III (Figs 5a and b). The cytopathic changes such as perinuclear clear halos, abnormal pyknotic nuclei, multinucleation, and single cell keratinisation were variable in frequency and predominantly evident in the most superficial layers of the neoplastic epithelium (surface koilocytosis). $\operatorname{In}^{\infty}$

some cases hyperkeratosis was present.
The total number of cases of CIN irrespective of

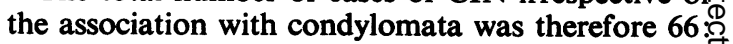
30 of CIN II and 36 of CIN III. The data are sum $\frac{\mathbb{2}}{2}$ marised in Table 1 . The histology of the vaginal, vulvar, and penile condylomata acuminata was con sistent with the clinical diagnosis. 


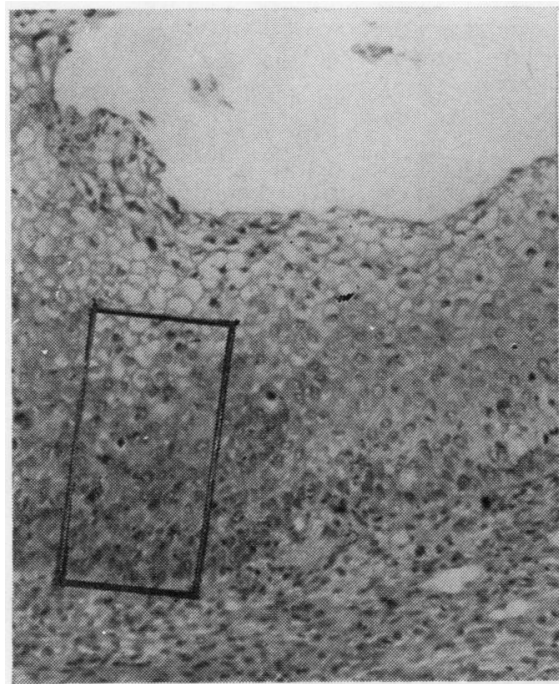

3a

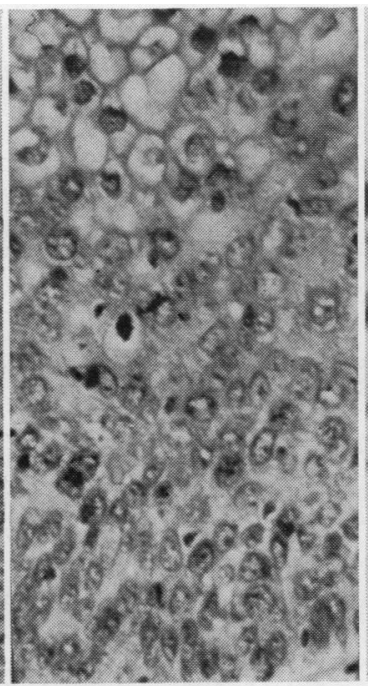

$3 \mathrm{~b}$

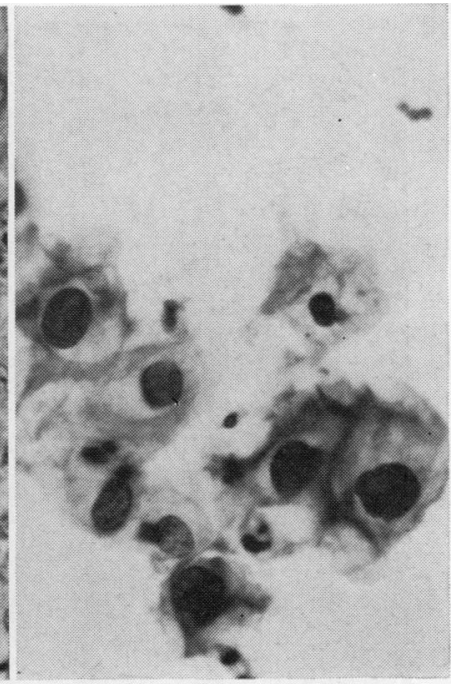

$3 c$

Fig. 3a Flat condyloma type 1 (right end of the epithelium) and transition to initial CIN with koilocytosis (left end). Haematoxylin and eosin $\times 100$

Fig. 3b Enlarged area of A: maturation arrest and abnormalities of the nuclei in the deep layers of the epithelium. Haematoxylin and eosin $\times 250$

Fig. 3c Cytological appearance of CIN II with koilocytosis: perinuclear halos are present.

Papanicolaou $\times 400$

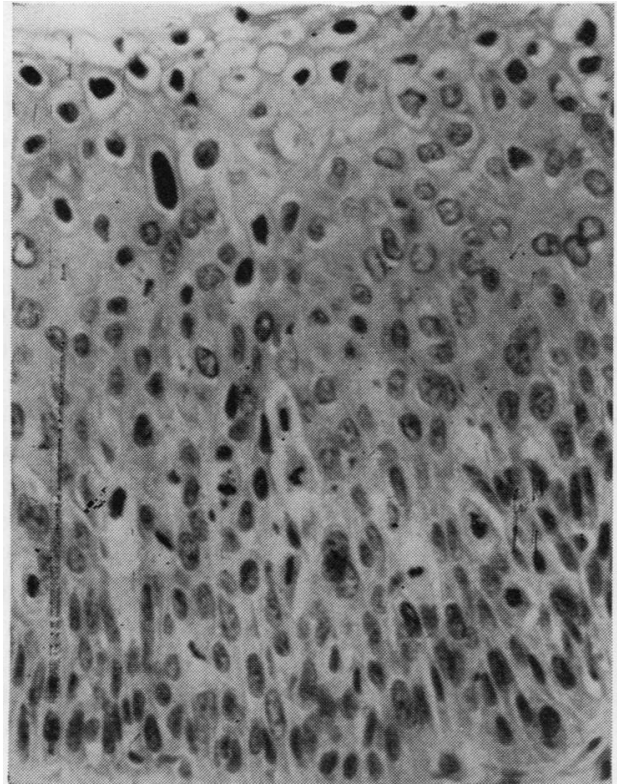

$4 a$

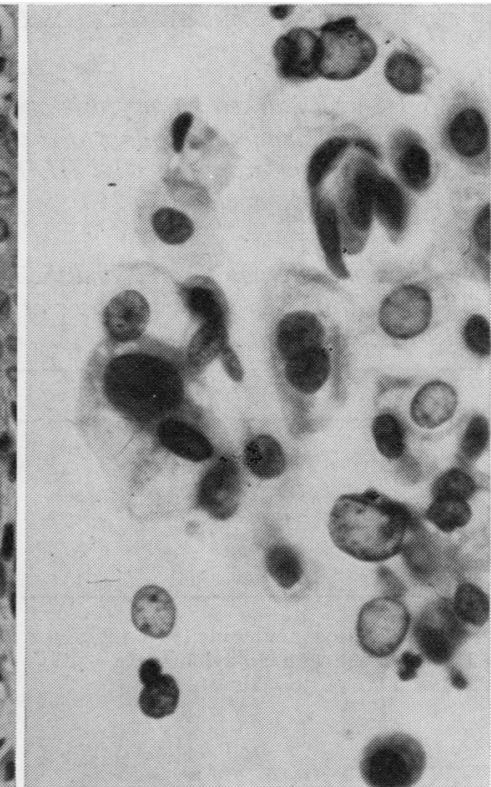

$4 b$

Fig. 4a CIN II with koilocytosis. The maturation arrest with nuclear abnormalities involves predominantly the lower and the intermediate layers, whereas cytopathic changes are recognisable in the superficial layers of the epithelium. Haematoxylin and eosin $\times 250$

Fig. 4b Cytological appearance of CIN II: the cytoplasms in part are fairly large and pleomorphic and contain small halos. The nuclei are atypical, bizarrely shaped and often multiple. Papanicolaou $\times 400$ 


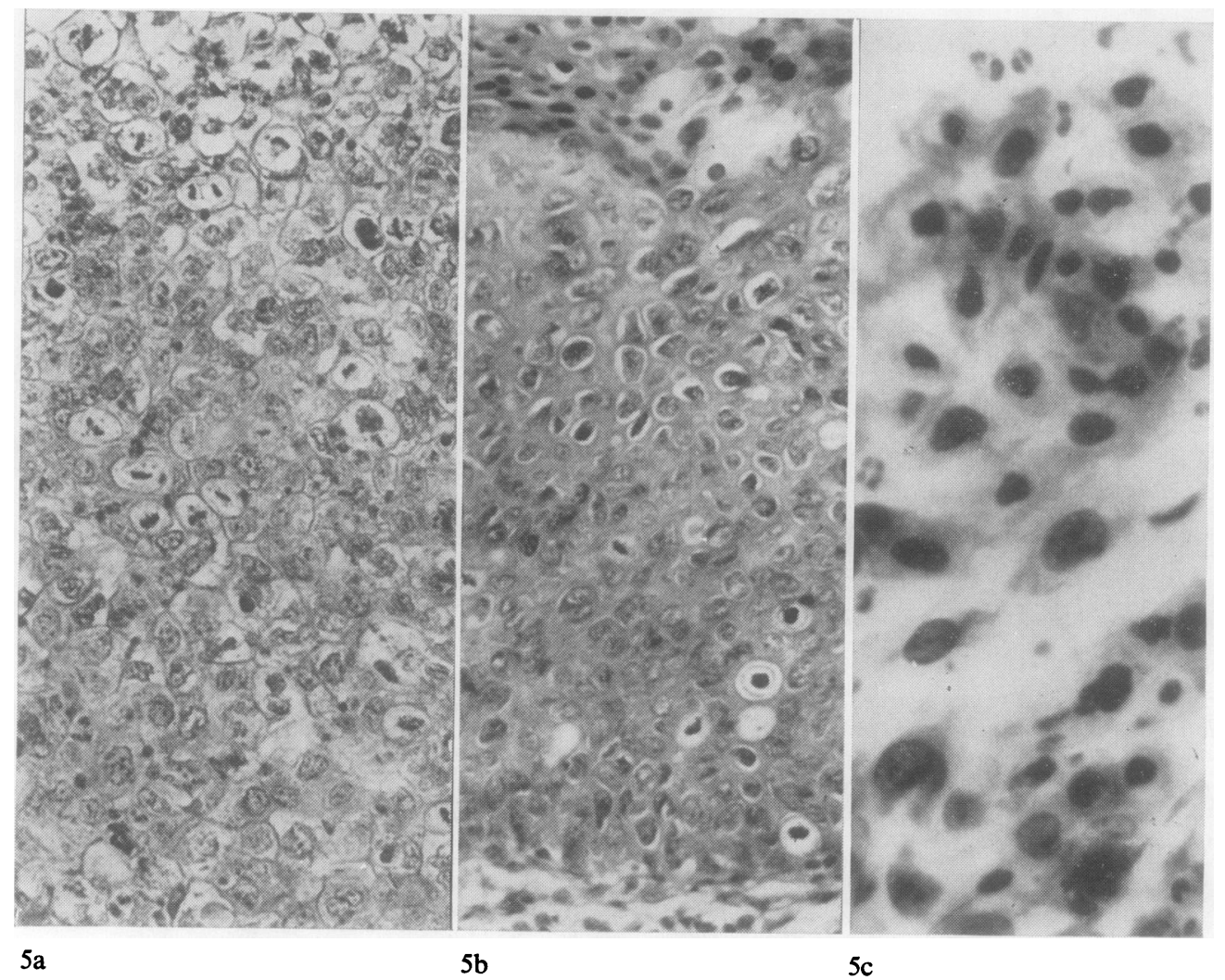

Fig. 5a CIN III with marked koilocytosis and a high mitotic index. Haematoxylin and eosin $\times 250$

Fig. 5b CIN III with moderate koilocytosis and hyperkeratosis. Haematoxylin and eosin $\times 250$

Fig. 5c Cytological appearance of CIN III. The cells show marked nuclear atypia. Perinuclear halos are very rare and small. Papanicolaou $\times 250$

Table 1 Cervical condylomata types 1 and 2 and their association with CIN in relationship to the presence of koilocytosis in cervical smears from 202 patients

\begin{tabular}{|c|c|c|c|c|}
\hline & Condyloma* & CIN II & CIN III & Total \\
\hline $\begin{array}{l}\text { Condyloma type } 1 \\
\text { Condyloma type } 2 \\
\text { Absence of }\end{array}$ & $\begin{array}{r}104 \\
32\end{array}$ & $\begin{array}{r}12 \dagger \\
6 \dagger\end{array}$ & $\begin{array}{r}15 \dagger \\
6 \dagger\end{array}$ & $\begin{array}{r}131 \\
44\end{array}$ \\
\hline $\begin{array}{l}\text { condylomata } \\
\text { Koilocytosis in }\end{array}$ & - & 12 & 15 & 27 \\
\hline cytology & 136 & 30 & 36 & 202 \\
\hline
\end{tabular}

*Group 1 cases with cervical condylomata only $(n=136)$.

† Group 2 cases of CIN associated with condylomata $(n=39)$.

$\ddagger$ Group 3 cases of CIN with koilocytosis $(n=27)$.

\section{CYTOLOGY}

The cytological features of the CVE smears of the 136 cases with histologically proven condyloma were characterised by the presence of sheets of cells with various degrees of dyskeratosis and sheets or cohesive clusters of superficial and intermediate cells with large cytoplasm and a perinuclear clear halo (koilocytotic atypia) (Fig. 1b). The nuclei were often eccentric, occasionally enlarged, with pale dustyô chromatin, and resembled those described as condylomatous intermediate cells ${ }^{20}$ but were more? often hyperchromatic and pyknotic. The cytoplasm was usually markedly polychromatic, whereas single cell cytoplasmic keratinisation and phagocytosis of granulocytes were rare. Multinucleated cells were ${ }^{\mathcal{N}}$ quite numerous in some cases, and their overlapping and hyperchromatic nuclei showed a blackberry-w shaped pattern. In general, a large number of multinucleated cells, isolated keratinised cells, and phagooo cytosis of granulocytes were related to the cases with condyloma type 2 (Fig. 2b). The cytological follow up of 55 cases with both condypmata type 1 and 20 showed no koilocytotic cells in smears of $60 \%$ of the women after six months, while they persisted unchanged in $40 \%$.

The cytological findings of the 66 cases in whicho the histology showed either CIN with koilocytosis or the combined presence of condylomata and CINO 
were similar (Figs 3c, 4b, 5c). In general, neoplastic cells with the characteristic perinuclear halo were rare. They were more common in CIN II than in CIN III. In the smears from cases with CIN III with koilocytosis, the atypical cells were predominantly single and roundish with little cytoplasm. However, some of them had a moderately large pleomorphic cytoplasm which was either acidophilic or almost unstained. The atypical nuclei were hyperchromatic, pyknotic, bizarrely shaped, often multiple, and often associated with retrogressive changes. Perinuclear halos were small and rare. A variable number of neoplastic cells without koilocytosis and of nonmalignant koilocytes was also found.

CYTOHISTOLOGICAL CORRELATION (Table 2) The cytological diagnosis in 125 of the 136 cases of cervical condylomata (group 1) had been simply koilocytosis, whereas in the remaining 11 cases the diagnosis of CIN II with koilocytosis was subsequently revised and downgraded. The histological pattern of five of these 11 cases was consistent with condyloma type 2 . The cytohistological correlation of the 66 cases of either CIN with koilocytosis or CIN with accompanying condylomata showed that in 18 the cytological diagnoses had not reflected the actual degree of severity of the lesion. However, the revision reconfirmed the original underestimated cytological diagnoses in five cases of CIN II and nine of CIN III, whereas in four cases of CIN III the smears were reclassified as inadequate.

Table 2 Cytohistological correlation

\begin{tabular}{lllll}
\hline Cytology & Histology & \multicolumn{2}{c}{ Total } \\
\cline { 2 - 4 } & Condyloma & \multicolumn{2}{c}{ CIN II +} & \multicolumn{2}{c}{ CIN III + } \\
& & $K \pm C$ & $K \pm C$ & \\
\hline Koilocytosis & $125(92 \%)$ & 5 & $4 *$ & 134 \\
CIN II + K & 11 & $25(83 \%)$ & 9 & 45 \\
CIN III + K & - & - & $23(64 \%)$ & 23 \\
Total & 136 & 30 & 36 & 202 \\
\hline
\end{tabular}

$\mathrm{K}=$ koilocytosis $; \mathrm{C}=$ condyloma

*Superficial smears.

\section{COLPOSCOPY AND COLPOSCOPIC-}

HISTOLOGICAL CORRELATION

Three main colposcopic patterns were seen in 81 of 136 cases $(59 \%)$ with histologically proven condylomata. In 38 cases we found leukoplakia-like condylomatosis made up of sharply defined areas of different shapes and sizes, whitish-ground glass in colour, and slightly raised above the mucosa of the portio with either straight or branching vessels. In 37 cases we found white-patches condylomatosis showing multiple, small, roundish, smooth, and whitish formations which were slightly raised above the ectocervical mucosa and surrounded by a thickening at the periphery. In the remaining six cases we found florid condylomatosis revealing a multicentric, whitish, elevated proliferation on the ectocervix with a rough "cobblestone"-like surface, which was poorly vascularised and did not show atypical vessels. In no case of condyloma was there colposcopic evidence of atypical transformation.

In the 18 cases of CIN II associated with condylomata, the latter were recognised colposcopically in 17, of which 10 showed a leukoplakia-like pattern and seven white patches. In the 21 cases with CIN III with condylomata, colposcopy showed mixed patterns in seven.

\section{ELECTRON MICROSCOPIC FINDINGS}

Spherical viral particles, approximately 350 to $400 \AA$ in diameter and morphologically identical to human papilloma virus (Figs 6,7), were found in $12(57 \%)$ of the 21 cervical lesions examined. Ten of the positive lesions had been identified on semithin sections as condylomata. In two of these cases the histology of the whole biopsy material had shown CIN III adjacent to the condyloma. In the other two cervical lesions with viral particles, semithin sections showed CIN II with koilocytosis. Of the nine cervical lesions that exhibited no viral particles, seven were condylomata and two CIN III with koilocytosis.

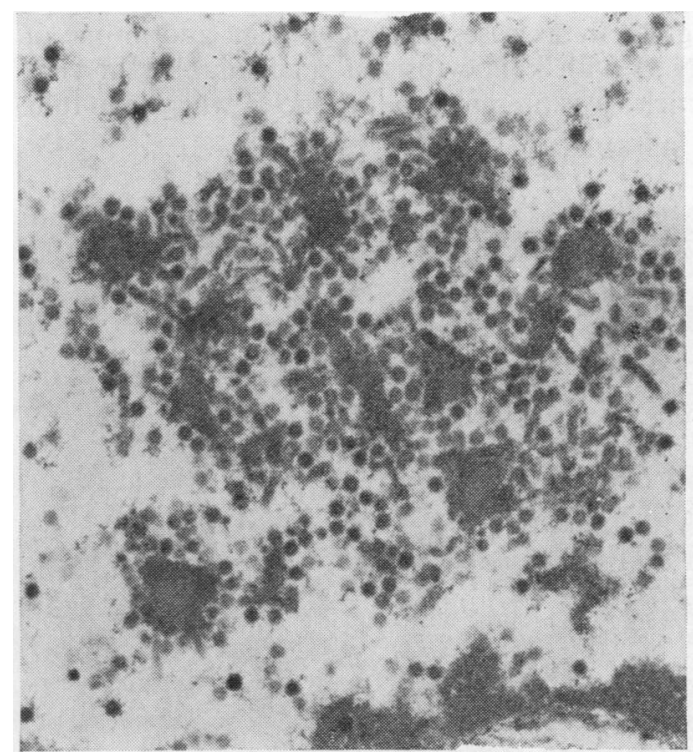

Fig. 6 Intranuclear viral particles grouped around chromatin clumps or independent in the nucleoplasm. $\times 61000$ 


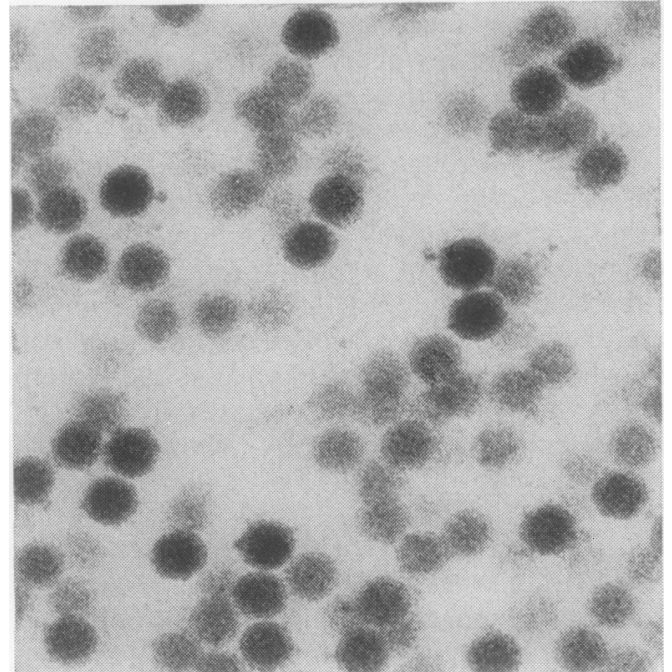

Fig. 7 A higher magnification of intranuclear viral particles showing a dense core with a surrounding clear halo. Note their regular form and size. $\times 177000$

The viral particles were contained in the nuclei of superficial epithelial cells. Most particles were single and either freely scattered throughout the nucleoplasm or closely associated with chromatin clumps. Others were assembled in small or large clusters in the nucleoplasm. Viral particles of the cytoplasm were found in cells with a ruptured nuclear envelope (Fig. 8). In six cases of condylomata and in one of CIN II with koilocytosis, a small number of viral particles was present in a few nuclei, whereas in four condylomata cases and in the other case of CIN II with koilocytosis there were many nuclei with viral particles and most of them had a high concentration $\underset{\vec{s}}{\overrightarrow{2}}$ of viral particles.

In the cells of both condylomata and CIN II with koilocytosis, two types of nuclei with viral particless were observed. Many were enlarged, had irregularo profiles and a clear aspect, contained large clumpsy of chromatin mainly attached to the nuclear envelope, and showed no separation between the $\vec{\circ}$ nuclear envelope and clumped chromatin (Fig. 9aand b). Others with a round shape and a markedle diminished size were striking because of the coms pact arrangement of their chromatin clumps. The margins of the chromatin were prominent and the nuclear envelope unidentifiable (Fig. 10a and b) The nuclei were surrounded by a large clear arew almost devoid of cytoplasmic organelles. In this area a few cytoplasmic remnants were recognisable, and they were scattered sparsely or sometimes conz densed and aligned on the outer margin of the nucle Occasionally glycogen-like material such as rare isolated granules was observed. The clear perio nuclear area was delineated at the periphery by $\vec{a}$ dense narrow band of cytoplasm containing irregue larly arranged bundles of tonofilaments. The boundary between the perinuclear and outer area of the cytoplasm was sharply defined.

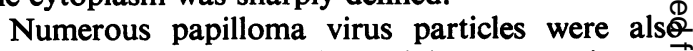
observed in the vaginal condyloma acuminatur $\overrightarrow{\vec{B}}$ examined. They were dispersed or arranged in $\bar{\alpha}$ paracrystalline fashion in the enlarged nuclei of the superficial epithelial cells, which showed dense peripheral and clear perinuclear areas of cytoplasị as described above.

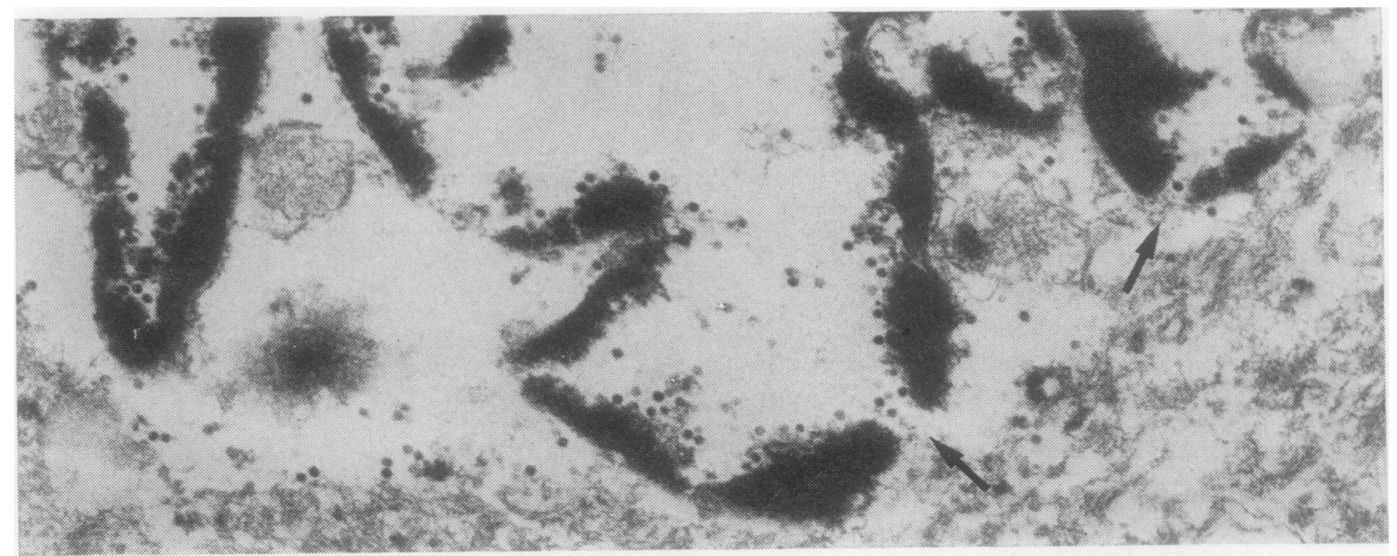

Fig. 8 Part of a nucleus showing the ruptured nuclear envelope (arrows). Single viral particles can be seen in the cytoplasm. $\times 28000$ 

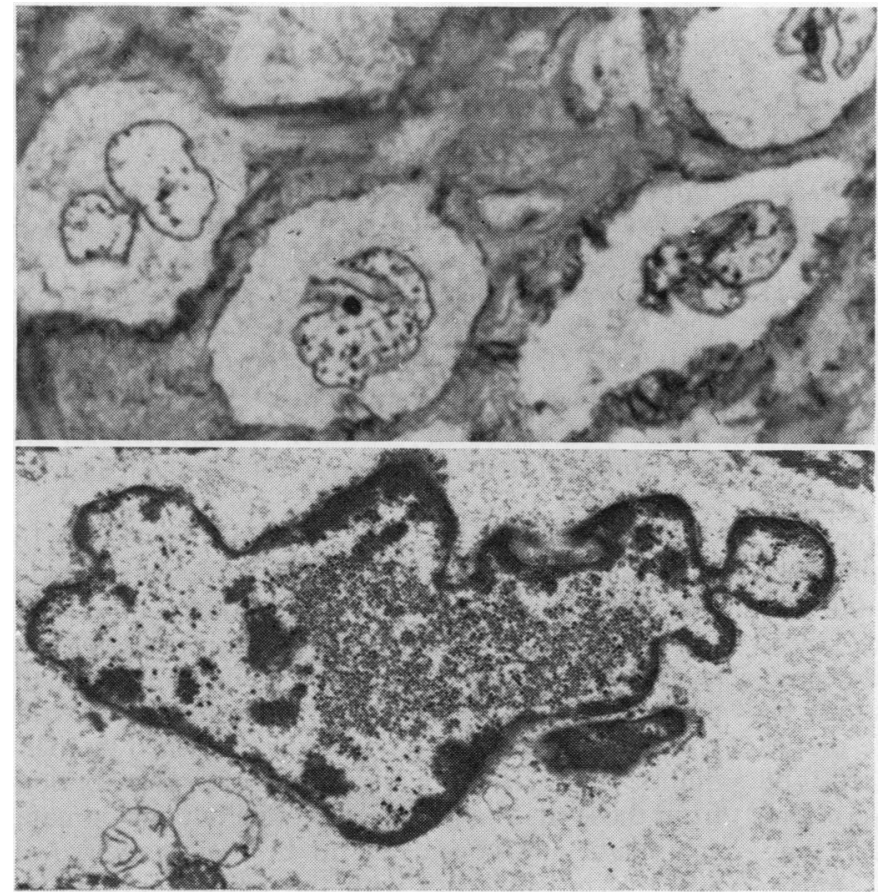

Fig. 9a Benign koilocytes with large nuclei: the morphology of the nuclei in semithin section. Methylene blue-azure II $\times 1000$

Fig. 9b A large nucleus with irregular outline showing a thin margination of the clumped chromatin. A cluster of viral particles independent of chromatin can be seen in the nucleoplasm. $\times 14000$

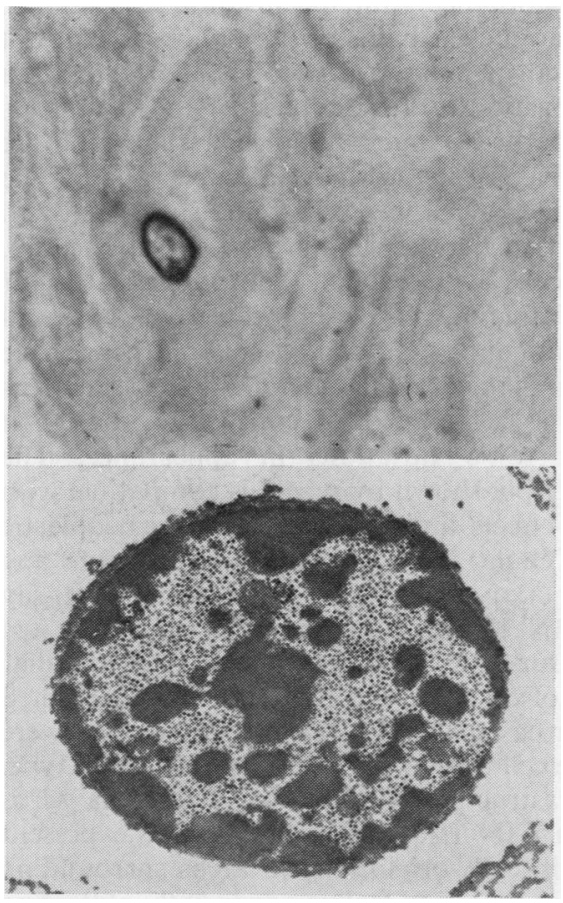

Fig. 10a Small nuclei in a semithin section: prominent margination of the chromatin. Methylene blue-azure II $\times 1000$

Fig. 10b A small, round nucleus with large compact clumps of chromatin. Note the nucleoplasm entirely filled with viral particles. $\times 16000$ 


\section{Discussion}

The results show that the cytological diagnosis of koilocytosis without marked nuclear abnormalities in CVE smears was, on the whole, reliable with reference to the presence of condylomata of the cervix. However, it is recognised that the reverse may not be true. ${ }^{25}$ The occasional overestimation of the cytological diagnosis and its interpretation as CIN II was probably related to the traditional cytological approach. ${ }^{11}$ However, since in about half of the overestimated cases histology showed a condyloma type 2, which more closely resembles CIN than does type 1 , the low grading after revision was limited to less than $5 \%$ of the cases. We did not observe marked nuclear atypia indicative of a malignancy such as that described for condylomata acuminata. ${ }^{25}$ On the contrary, there was underestimation of the cytological diagnosis of CIN when koilocytosis was a prominent feature. The decreased accuracy of cytology in some of these cases may be related to the peculiar histological structure of the lesions, with well-preserved neoplastic cells of diagnostic value located in the deeper layers and koilocytotic cells not readily recognised as being neoplastic being found superficially. The smears taken from some of the cases of CIN with koilocytosis, and particularly from those with hyperkeratosis, showed the presence of parakeratotic cells and abnormal, pleomorphic cells but which appeared mature with a large cytoplasm. The resulting pattern corresponded in part to those described as pleomorphic parakeratosis and pleomorphic keratinising dysplasia. ${ }^{26}$

Although the follow-up was short and incomplete, it seems that the cytological changes of condylomata disappear at least temporarily in a high percentage of the cases. ${ }^{12} 152027$ In view of the fact that condylomata type 1 and particularly type 2 may be interpreted histologically as mild or moderate dysplasia and koilocytosis in smears as mild dysplasia, the reported high regression rate of these lesions finds a partial explanation. Because there is frequent spontaneous regression and because their natural history is uncertain, small condylomata of the cervix should not be overtreated but kept under clinical and cytological control. The incidental finding of penile condylomata acuminata in the sexual partners of two patients stresses the indication for the systematic examination of the couple. ${ }^{28} 29$ The colposcopic findings were consistent with the histological report in about $60 \%$ of the cases with condylomata and were essentially the same in the cases with condylomata and CIN. In most of the cases of CIN with or without condylomata, the colposcopic picture was, however, dominated by the areas of atypical transformation from which the biopsies were taken. Therefore, the absence of accompanying condyloma in some cases of CIN with koilocytosis may have been a sampling error.

In keeping with the rarity of papillomatous condylomata of the cervix, the colposcopic pattern of florid condylomatosis was the least common. The leuko- $\frac{\mathbb{Q}}{2}$ plakia-like pattern had to be distinguished from the true mosaic on the basis of the appearance of thes vessels, whereas the white-patches condylomatosis? had to be differentiated from cornified glandular $\overrightarrow{-}$ outlets. The latter was the most difficult type to recognise at colposcopy, and for its identification the preceding cytological diagnosis of koilocytosis was $\omega$ very helpful.

The presence of intranuclear viral particles in $12 \mathrm{c}$ of 21 cases examined expands our own results on four of the present cases ${ }^{14}$ and confirms those pub-o lished by others. ${ }^{15-19}$ Frequently, as in condylomata acuminata, a few viral particles and only a smallz number of koilocytes were present. The viral particles detected could not be distinguished by their $\vec{\bullet}$ number, ultrastructure and intranuclear distribution $\propto$ from those that have been identified in condylomata acuminata and considered to be their aetiologicalo agent. ${ }^{2}$ The similarity with the findings in condy-lomata acuminata suggests that the cervical infection by a papilloma virus is responsible for the cytopathic융 changes of condylomata non-acuminata as well as of $\supseteq$ CIN. In accordance with the histological findings, $\overrightarrow{0}$ the clear perinuclear halos of the koilocytes $\operatorname{did}$ not $^{3}$ contain glycogen and they may be related to oedema? and vacuolisation of the cytoplasm. ${ }^{30}$

It is noteworthy that in published reports in the examples given of the histological appearance of the various grades of CIN, often in the superficial and 3 . occasionally in the deeper layers of the epithelium, there are cells with evident koilocytosis. ${ }^{31} 32$ Our histological findings clearly indicate that the smallo and predominantly flat condyloma of the uterine cervix, also named noncondylomatous wart viruso infection, ${ }^{17}$ is a well-defined entity even though it may show some variations in appearance. The degree of atypia shown by type 2 is compatible withN cytopathic effects and is not necessarily neoplasticN in origin. Cellular pleomorphism does not allow anyo clear distinction from CIN. Also we cannot say whether CIN II and III with koilocytosis are juste CIN with superimposed viral infection or peculiaros precursors of cervical carcinoma. It should be noted that all our cases of CIN III with koilocytosis wereof the large cell type and never of the small cell type. $\overrightarrow{\mathbb{D}}$

The ultrastructural findings of papilloma virus particles in CIN II-derived cells as in the present series and in cells originating in areas surrounding carcinoma in $\operatorname{situ}^{17}$ and from a cervix with infiltratingo 
carcinoma $^{14}$ do not support any causal relationship between papilloma virus infection and cervical neoplasia. The same applies to the coexistence of condylomata and CIN and to the apparent transition from the first to the latter. Undoubtedly, the cases of proven progression of "verrucous dysplasia" to $\mathrm{CIN}^{33}$ and those of development of mild dysplastic lesions with koilocytic atypia after cone biopsy for CIN III ${ }^{27}$ point to an interaction of papilloma virus infection of the human uterine cervix with the premalignant and malignant transformation of the cells. Should this be confirmed, then the hypothesis, proposing the existence of several pathways, both infectious $^{34}$ and noninfectious, ${ }^{35}$ leading to cervical carcinoma, would gain ground.

We thank Ms B Johnston for her assistance in preparation of the manuscript. This study was partially supported by grant no 780286096 from the Consiglio Nazionale delle Ricerche, Rome.

\section{References}

${ }^{1}$ Dunn AEG, Ogilvie MM. Intranuclear virus particles in human genital wart tissue: observations on the ultrastructure of the epidermal layer. J Ultrastruct Res 1968; 22:282-95.

2 Oriel JD, Almeida JD. Demonstration of virus particles in human genital warts. Br J Vener Dis 1970;46:37-42.

${ }^{3}$ Coggin JR, zur Hausen H. Meeting report: Workshop on papilloma-viruses and cancer. Cancer Res 1979;39:545-6.

${ }^{4}$ zur Hausen H, Meinhof W, Sheiber W, Bornkamm GM. Attempts to detect virus-specific DNA sequences in human tumors. I. Nucleic acid hibridizations with complementary RNA of human wart virus. Int $J$ Cancer 1974;13:650-6.

5 Almeida JD, Oriel JD, Stannard LM. Characterization of the virus found in human genital warts. Microbios 1969; 3:225-32.

'Friedman JM, Fialkow PJ. Viral "tumorigenesis" in man: cell markers in condylomata acuminata. Int $J$ Cancer 1976;17:57-61.

7 Oriel JD. Natural history of genital warts. Br J Vener Dis $1971 ; 47: 1-8$

${ }^{8}$ Oriel JD. Anal warts and anal coitus. Br J Vener Dis 1971; 47:373-76.

${ }^{9}$ Waugh M. Condylomata acuminata. Br Med J 1972;ii: 527-8.

${ }^{10}$ zur Hausen H. Human papilloma viruses and their possible role in squamous cell carcinomas. Curr Top Microbiol Immunol 1978;78:1-30.

11 Meisels A, Fortin R, Roy M. Condylomatous lesions of the cervix. II. Cytologic, colposcopic and histopathologic study. Acta Cytol 1977;21:379-90.

${ }^{12}$ Meisels A, Fortin R. Condylomatous lesions of the cervix and vagina. I. Cytologic patterns. Acta Cytol 1976;20: 505-9.

${ }^{13}$ Koss LG, Durfee GR. Unusual patterns of squamous epithelium of the uterine cervix. Cytologic and pathologic study of koilocytotic atypia. Ann NY Acad Sci $1956 ; 63: 1245-61$.
${ }^{14}$ Della Torre G, Pilotti S, De Palo G, Rilke F. Viral particles in cervical condylomatous lesions. Tumori 1978;64:54953.

${ }^{15}$ Laverty CR, Russell P, Hills E, Booth N. The significance of noncondylomatous wart virus infection of the cervix transformation zone. A review with discussion of two illustrative cases. Acta Cytol 1978;22:195-201.

${ }^{16}$ Laverty CR, Booth N, Hills E, Cossart Y, Wills EJ. Noncondylomatous wart virus infection of the postmenopausal cervix. Pathology 1978;10:373-8.

${ }^{17}$ Reid R, Laverty CR, Coppleson M, Isarangkul W, Hills E. Noncondylomatous cervical wart virus infection. Obstet Gynecol 1980;55:476-83.

${ }^{18}$ Hills E, Laverty CR. Electron microscopic detection of papilloma virus particles in selected koilocytotic cells in a routine cervical smear. Acta Cytol 1979;23:53-6.

19 Morin C, Meisels A. Human papilloma virus infection of the uterine cervix. Acta Cytol 1980;24:82-4.

${ }^{20}$ Komorowski RA, Clowry LJ. Koilocytotic atypia of the cervix. Obstet Gynecol 1976;47:540-4.

${ }^{21}$ Purola E, Savia E. Cytology of gynecologic condyloma acuminatum. Acta Cytol 1977;21:26-31.

22 Okagaki T, Clark BA, Brooker DC, Williams PP. Koilocytosis in dysplastic and reactive cervical squamous epithelium: an ultrastructural study. Acta Cytol 1978; 22:95-8.

${ }^{23}$ Richart RM. Colpomicroscopic studies of cervical intraepithelial neoplasia. Cancer 1966;19:395-405.

${ }^{24}$ Richart RM. Natural history of cervical intraepithelial neoplasia. Clin Obstet Gynecol 1967;10:748-84.

${ }^{25}$ Koss LG. Diagnostic cytology and its histopathologic bases. 3rd ed. Philadelphia, Toronto: Lippincott, 1979:270-84.

${ }^{26}$ Patten SF Jr. Diagnostic cytopathology of the uterine cervix. 2nd ed. Basel: S. Karger, 1978:146-70.

${ }^{27}$ Kirkup W, Singer A, Hill AS. Follow-up of women treated for cervical precancer: an argument for a more rational approach. Lancet 1979 ;ii :22-4.

${ }^{28}$ Cocks PS, Peel KR, Cartwright RA, Adib R. Carcinoma of penis and cervix (letter to the Editor). Lancet 1980;ii: 855-6.

${ }^{29}$ Kessler II. Human cervical cancer as a venereal disease. Cancer Res 1976;36:783-91.

${ }^{30}$ Laurent R, Coume-Marquet S, Kienzler JL, Lambert D, Agache P. Comparative electron microscopic study of clear cells in epidermodysplasia verruciformis and flat warts. Arch Dermatol Res 1978;263:1-12.

${ }^{31}$ Poulsen HE, Taylor CW. Histological typing of female genital tract tumours. International histological classifcation of tumors no. 13. Geneva: World Health Organisation, 1975.

32 Riotton G, Christopherson WM. Cytology of the genital tract. International histological classification of tumors no. 8. Geneva: World Health Organisation, 1973.

33 Johnson LD. Dysplasia and carcinoma in situ in pregnancy, In: Norris HJ, Hertig AT, Abell MR, eds. The uterus. Baltimore: Williams \& Wilkins, 1973:382-412.

${ }^{34}$ McDougall JK, Galloway DA, Fenoglio CM. Cervical carcinoma: detection of herpes simplex virus RNA in cells undergoing neoplastic change. Int J Cancer 1980; 25:1-8.

${ }^{35}$ Ashley DJB. The biological status of carcinoma in situ of the uterine cervix. J Obstet Gynaecol Br Comm 1966;73: 372-81.

Requests for reprints to: Dr F Rilke, Department of Pathology and Cytology, Istituto Nazionale per lo Studio e la Cura dei Tumori, Via Venezian 1, 20133 Milan, Italy. 